\title{
Oral Rehabilitation of Severe Early Childhood Caries and Associated Challenges: Two Case Reports
}

\author{
Opinya $\mathrm{GO}^{1 *}$, Chepkwony $\mathrm{F}^{2}$ and Gichu $\mathrm{N}^{2}$ \\ ${ }^{1}$ Professor of Paediatric Dentistry Department of Paediatric Dentistry, School of Dental Sciences, College of Health Sciences, University of \\ Nairobi, Kenya \\ ${ }^{2}$ Department of Paediatric Dentistry \& Orthodontics, School of Dental Sciences, University of Nairobi, Kenya
}

Received: 眥 April 16, 2018; Published: 㘹 May 11, 2018

*Corresponding author: Gladys Opinya, Department of Paediatric Dentistry \& Orthodontics, School of Dental Sciences, College of Health Sciences, University of Nairobi, Kenya

\begin{abstract}
Early Childhood Caries (ECC) is defined in the Guidelines of the American Association of Paediatric Dentists as a condition in children aged between 3-5 years where there is "The occurrence of one or more decayed (not cavitated or cavitated lesions). Teeth are missing (due to decay), or restored tooth surfaces" in any primary tooth in a child 71 months and below [1]. Also, the filled smooth surfaces in primary maxillary anterior teeth, or a decayed, missing or filled a score of $>4$ (age 3), $>5$ (age 4), or $>6$ (age 5) surfaces constitutes Severe-ECC. ECC is a public health problem with biological, social and behavioral diet [2]. Amongst the most prevalent chronic disease childhood is dental caries [3].Caries in very young children known as Early Childhood Caries (ECC) may be defined as at least one carious lesion affecting an anterior maxillary tooth in preschool- aged children [4]. The age for ECC is defined from 3years to 5 years where there is one or more cavitated, missing (due to caries), or filled smooth surfaces in primary maxillary anterior teeth. A decayed, missing or filled a score of $\geq 4$ surfaces age three-years, $\geq 5$ tooth surfaces for age 4years or $\geq 6$ affected tooth surfaces for age five years constitute severe-ECC [5]. In Kenya, a prevalence of $63.5 \%$ has been reported with a mean dmft of 2.95 among 3-5-yr old children and in a different study a mean dmft of 1.35 and 1.88 for 3yr-olds and five-year-olds respectively [6,7]. Milnes [5] show that carries on maxillary anterior primary dentition has the highest prevalence in Africa [4].The risk factors which have been associated with ECC the child's low birth weight, maternal education, and duration of feeding at infancy and toddler stage, low socioeconomic status among others $[3,6]$.Dental caries is an infectious disease that is modified by diet. The biological mechanisms of dental caries are well established [2].
\end{abstract}

\section{Introduction}

It is a disease with some critical aetiological factors each of which must be simultaneously present to initiate and progress the disease. Dental caries in early childhood is a highly virulent type, and it causes extensive destruction of the deciduous teeth, often very rapidly. Much research into the aetiology and prevention of ECC has focused on the dietary substrate component leading to the terms 'baby bottle tooth decay' and 'nursing caries.' More recent research confirming the relative role of the microbial (plaque) and tooth resistance factors have fostered a better appreciation of the

biological risk and protective factors in ECC. The factors associated with ECC are fermentable carbohydrates (substrate); cariogenic microorganisms, the frequency of intake of refined sugars, tooth enamel defects such as enamel hypoplasia; and the socioeconomic state of the caregiver [8,9]. A new pathogen S. wiggsiea has been associated with severe early childhood caries may be due to extremes in one or more of the three factors above. Streptococcus mutans and streptococcus Wiggsiae in dental plaque metabolize sugars and starches to produce acids, which lowers the $\mathrm{pH}$ in the 
mouth and promotes loss of minerals from the tooth surface [1012]. Minerals in the oral cavity including fluoride are re deposited on the tooth surface once the neutral $\mathrm{pH}$ is restored (generally after approximately $20 \mathrm{~min}$ ). This process is dynamic and as long as minerals are replaced the tooth Surface remains sound and intact. However, a prolonged $\mathrm{pH}$ drop and the total net loss of minerals lead to a weakening and eventual break down (cavity) in the tooth surface. Also a susceptible tooth surface/host.

The short-term consequences of untreated decay in children's teeth include pain with up to $12 \%$ of 5 -year-olds reported to have experienced toothache, systemic infection, abscesses, surgery and general anaesthesia. Therefore a higher risk of hospitalisations may be required. Once decay has reached this stage, it is often difficult to manage in the dental set up [13]. Other short-term effects include irreversible pulpitis which may lead to premature loss of teeth. Untreated decay may lead to early loss of space contributing to malocclusion in the succeeding permanent dentition. Currently, there is substantial evidence that children who experience ECC are much more likely to develop other medical conditions. Also, poor dental health impacts upon the incremental growth and cognitive development by interfering with nutrition and concentration and school participation $[14,15]$. Child neglect is particularly appropriate given that psychosocially, poor oral health can affect not only speech production, communication, and self-image but also social functioning and hence further reduce an infants' quality of life. Severe ECC, when left untreated, is being recognized as part of the more general phenomenon of child neglect.

\section{Case 1}

A five and a half-year-old male who was accompanied by the mother presented to the paediatric dental clinic with a chief complaint of discolored teeth which were asymptomatic. The mother was concerned with the change in colour and associated cavitations on the teeth. The past dental history was that the mother had noticed the discolouration one year ago and she had taken the child to Kenyatta National Hospital dental clinic for treatment. Treatment at the dental facility was done restored under restraint. The children were unable to cooperate. Hence the mother opted to seek treatment at the pediatric department at the dental school. The child was seen by a dental intern in the department. However, he was very apprehensive, and he could not allow the intern to examine him. Hence he was referred to the postgraduate clinic for management. The child lived in a family of four in periurban Nairobi. He had a two-year-old sibling and was in school at preunit level. Both parents were in formal employment as teachers. There was no known medical condition in the family, and the family source of water was from the Nairobi County which has a fluoride content of $0.2 \mathrm{pp}$. Past medical history showed the child had no underlying medical problems. The prenatal period was uneventful the child was born in the hospital via standard delivery at full term; birth weight was $3.5 \mathrm{~kg}$ with no complications during and after delivery. He was fully immunised as per the Kenya Expanded Programme on Immunization requirement, and the developmental milestones were normal.

The child was breastfed up to 11/2 years (at night on demand and breast milk compliments were introduced at five months. The compliments consisted of on porridge, boiled pumpkin, banana but he was never a bottle fed. By the time the child was presenting to the clinic he rarely brushed, and if he did brush, he was unsupervised, and he used dentifrice Aqua-fresh adult formulation with a fluoride content of $1400 \mathrm{ppm}$ with no history of dental flossing. A further oral examination clinical examination was done, and it was noted that the boy was very apprehensive, but he was in fair medical condition with normal gait and posture. The face was symmetrical with competent lips. He had blue/gray pigmentation on the sclera which the parents said he was born with the condition. The facial profile was convex which is consistent with African descent. Intra Oral examination showed the child had poor oral hygiene with a plaque score of 2 according to Silness and Loe [16]. The soft tissues labially there was a discharging dental alveolar sinus associated with 52, 62 with inflamed marginal gingiva and had a gingival index of 1.0 according to Loe and Silness [17].He had a geographic tongue, and an abnormal tongue posture and the palate was normal. The dentition the child was in early mixed dentition with a distal step on the right and a flush terminal plane on the left side. The canines on the right were in a class II position while in the left class I relationship. The overjet and overbite were undeterminable due to the decay of the incisors tendency towards tongue thrusting. In the transverse position, there was a tendency towards scissors bite on the left. Erupting lower central incisors 31 and41' All the deciduous detention were present with a decayed filled, missing, dmft of 14. The carious tooth surfaces were as 55 Mesia buccal, 54Buccal palatal, 53Lingual 63Lingal palatal, 64Palatal, 65Buccal palatal 75Mesial lingual, 74Distal, occlusal lingual, buccal, 73Lingual, 72Lingual incisal, 83Lingual, 84Distal occlusal, lingual buccal, 85 lingual, occlusal 74Distal, occlusal, lingual (Figures 1-4). A sevenday diet chart analysis showed the child had three main meals were consumed in a day. The diet was balanced with carbohydrates forming the majority of the component. Intake of fermentable carbohydrates (sucrose) was frequent in the form of sugar in tea, doughnuts, and cakes. The mother reported that the 10 o'clock and lunch were taken in school and that the child was a poor feeder due to frequent complains of a toothache. The nutrition assessment indicated that the five years and five months old boy's weight for age of $14 \mathrm{~kg}$ was below the $3^{\text {rd }}$ percentile at zero percentile of the World Health Organisation reference standard. The weight for age z score WAZ -2.91 indicated that the child was underweight/ hence malnourished according to the WHO [18]. The height for age was $118 \mathrm{~cm}$ which was 1.1 percentile, and it was below the lowest WHO reference standard at third percentile. The HAZ score was $-2.30 \mathrm{SD}$ 
and below the $<-2$ SD cut off for the Kenya national anthropometric measurement which is a reference to the WHO median reference the child was moderately stunted in growth.
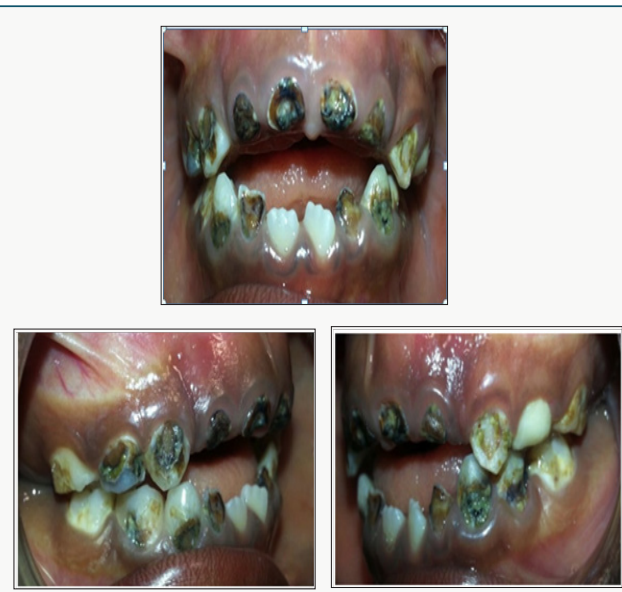

Figure 1: a. Intra-oral anterior view dated an abnormal tongue thrusting posture, anterior open bite, dental caries on all the deciduous teeth and newly erupting $31,41 . \mathrm{b}$. Moreover c. Intraoral right and left lateral views showing multiple carious teeth.
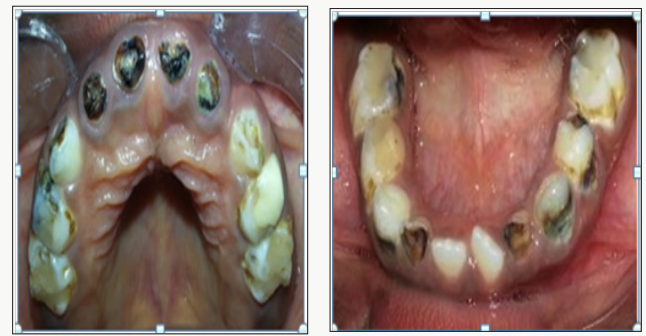

Figure 2: Intraoral photograph of the upper (a) and lower (b) occlusal views showing carious teeth and multiple composite restorations on occlusal of $55,54,65,75,84.84$ and failed restorations of 53,6,73,83.The child was in full deciduous dentition and the first permanent molars were not yet erupted.

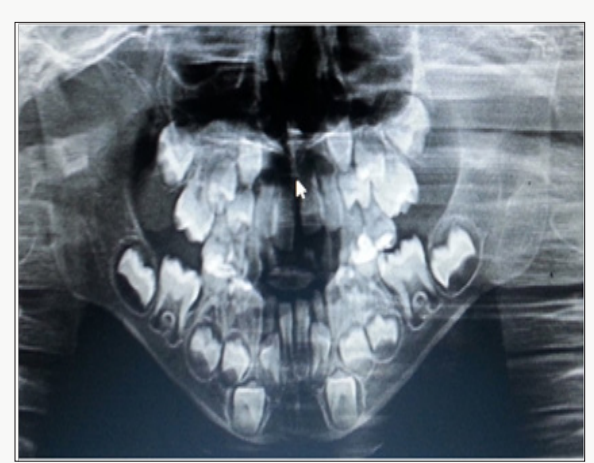

Figure 3: An orthopantomogram showed twenty-seven permanent teeth at various stages of development and eruption. Dental age 5-6 years. We were unable to take a good OPG due to the child's poor cooperation.

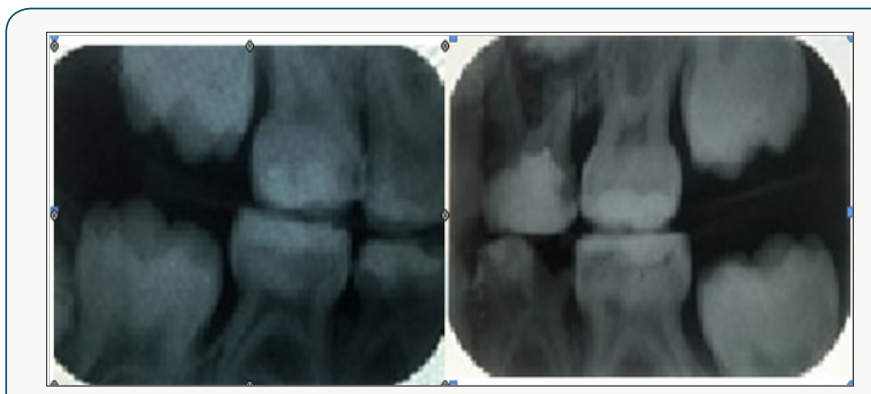

Figure 4: Bilateral bitewings with radiolucency consistent with dental caries on 55Mesial, 54Distal, 64Distaland on the mesial surface gingival floor and the restoration there is leakage 750 cclusal and secondary decay under the restoration, 74Distal occlusal 84Distal. Radio- opacity is consistent with restoration of 55Occlusal, 54occlusal, 64 occlusal, mesial and the distal root had radiolucency, 65 occlusal, 75 occlusal. 84 occlusal 85 occlusal, on the second molars and it rested on the canines in both jaws to minimise the drifting of the erupting first permanent molars and space loss Figure 5.

The body mass index was $10.1 \mathrm{~kg}$ per metre square which translated to a percentile of zero which was below the $5^{\text {th }}$ percentile on the WHO reference for gender and age for body mass index. The BAZ score was -5.68SD from the reference standard, and the child has severely wasted an indication of severe chronic malnutrition [19]. A diagnosis of a five year and 5.4-year-old African boy in early mixed dentition with erupting 31,41 . He had a Scissors bite on the left side also, an anterior open bite and tongue thrusting habit secondary to incisor tooth loss due to decay. The child severe early childhood caries, the dietary intake was highly cariogenic which was low in protein content with chronic malnutrition and a poor. The oral hygiene was poor with plaque score of 3 . The child's behavior rating was that it was definitely negative Frankl [19]. He had severe chronic malnutrition with weight and height for age which was below the third percentiles and a BMI that was below the 5th percentile on the WHO reference standard. The WAZ, $\mathrm{HAZ}$, and BAZ scores were all below <-2SD cut off point indicating the child suffered from chronic malnutrition, and he was wasted and stunted in growth and had with poor nutritional intake due to dental pain. He also had poor oral hygiene (plaque score of 3, Silness and Loe [16]) with geographic tongue. Severe dental caries on 55MOP, 54BP, 53L 63LP, 64P, 65BP 75ML, 74DOLB, 73L, 72LI, 83L, 84DOLB, 85LO 74DOL, retained roots 52, 51, 61, 62 and multiple failed restorations. The treatment objectives were the child's behavior management, dental caries control. Restoration of aesthetics, space management and nutritional counseling of the mother where there would be an increase in protein intake and a reduction in the snacks and institution of a preventative program with three months recall reinforcing the dietary intake and oral hygiene instructions. The treatment took slightly over twelve months, and several reasons necessitated the period. The parents 
could not afford the treatment at once although it was subsidised by the school hence appointments were scheduled so that the parents were able to pay. The treatment plan and management started with nonthreatening procedures so that the child could adapt to what he perceived as a threatening environment, hence preventive procedures of oral hygiene instructions and motivation, oral prophylaxis, and topical fluoride application/Diet counseling. Currently, the Dental school does not have an adequate operatory for general anaesthesia and even if the Dental school had such facility the parents could not have afforded the cost of having the child treated under general anesthesia [20-23]. Hence it is significant that the paediatric dentist interest the caregiver and walks through the treatment with them for the child to receive the prescribed treatment. For the restorative procedures restorations were made on tooth 55Mesial occlusal palatal; composite, a compomer and stainless steel crown (SCC)54, compomer on 53Lingual, 63Lingual, 73 Lingual, 83 Lingual Pulpotomy with stainless steel crowns on 84 and 85. Space maintenance was done using a band on 65 with loop extending to the 64 ; band on 75 with loop extending to the 74 , fissure Sealants of the first molars upon eruption. The extractions were the last invasive procedure to be done, and the over retained roots of 52,51,62,61 were extracted.
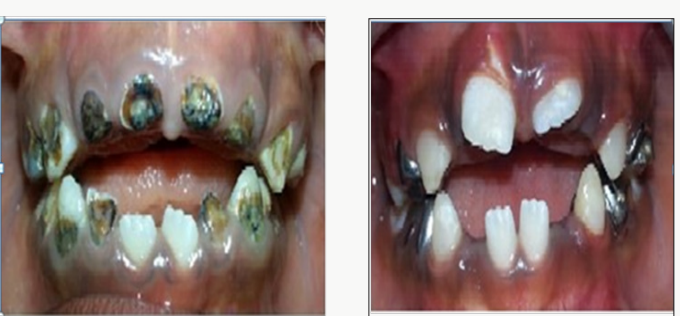

Figure 5: Intraoral a. Pre-op anterior view an abnormal tongue posture, anterior open bite, dental caries on all the deciduous teeth and newly erupting 31,41 b. Post-op anterior view is showing trauma to the gingiva labial to 11, high upper labial frenum attachment with midline diastema, erupting 11, 21 with a distal taper and localised opacities on the labial surface, multiple restorations, Stainless steel crowns and band and loop.
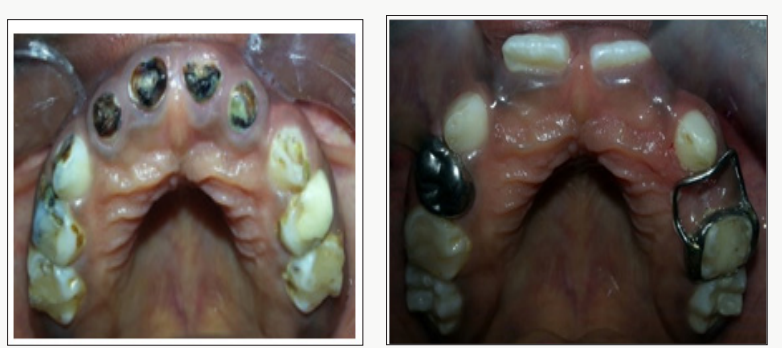

Figure 6: Intraoral a. Pre-of photographs of the upper occlusal view is showing carious teeth, multiple failed restorations, high palatal vault and prominent midpalatal raphae. b. Post-op photograph of upper occlusal view showing compomer restoration on 55, 53,63,65, Fissure sealants on 16, 26, Stainless steel crowns on 54, Band and loop on 65 , high palatal vault and prominent midpalatal raphae.
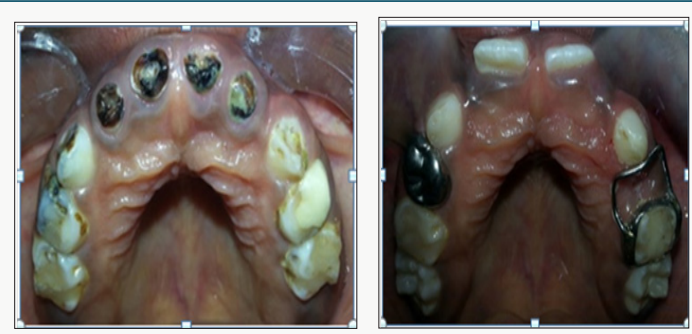

Figure 7: Intraoral a. Pre-op photograph of lower occlusal view showing carious teeth and multiple failed restorations b. Post-op photograph of lower occlusal view showing compomer on 83,73 , Fissure sealants on 46 , 36, Stainless steel crowns on $84,85,75$ and Band and loop on 75 .
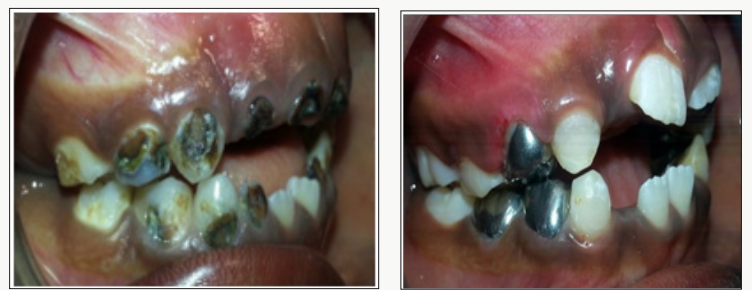

Figure 8: Intraoral a. Pre-op photograph of the right lateral view of carious teeth with multiple failed restorations and anterior open bite b. Post-op photograph of right lateral view showing compomer on 53,83 , Stainless steel crowns on $54,84,85$.
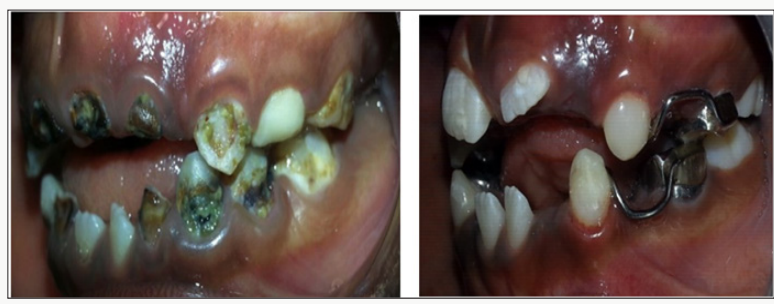

Figure 9: Intraoral a. Pre-op photograph lateral view is showing carious teeth and multiple failed restorations $b$. Post-op photograph of left lateral view showing compomer on 63,73 , Stainless steel crown on 75 and Band and loops on 65,75 .

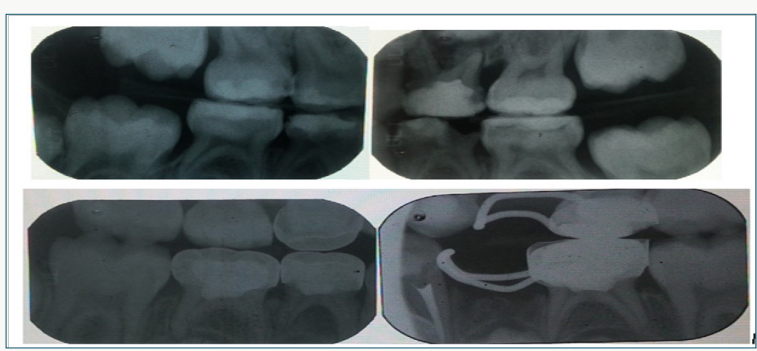

Figure 10: Pre-op bilateral bitewing is showing radiolucency consistent with dental caries on 55M, 54D in dentine, 85 underneath the restoration in continuity with the pulp, $84 \mathrm{D}, 64 \mathrm{D} 75 \mathrm{O}, 74 \mathrm{DO}$ in continuity with the pulp. Radio-opacity is consistent with restoration of $55 \mathrm{O}, 85 \mathrm{O}$, $84 \mathrm{O}, 64 \mathrm{MO}$ within the pulp chamber, $65 \mathrm{O}, 75 \mathrm{O}$, showing and $b$. Post-op bilateral bitewings showing radio-opacity consistent with restorations on 55, 63, pulpectomy on 73 , SCC on $54,84,85,75$ and Band and loop on 65,75 . 
The tooth $64 \mathrm{~b}$ was removed as there was no cervical crown to support a restoration while 74 developed a dental abscess. The behavior management was nonpharmacological a combined tell show and do, modeling and desensitization from the previous dental traumatic experiences. However, this case could have benefited from treatment under general anaesthesis, as this would have reduced the appointments remarkably and added to the quality of life of the child [19]. The child's behaviour fluctuated between Frankle's behavior rating of definitely negative and negative for the first two months, and it was noted that during this time there was minimal improvement in the oral hygiene as the plaque sure remained between 2-3 according to Loe and Silness [17]. However, in the third month after several teeth had been treated the child becomes cheerful and positive. It was also observed the positive behavior was sustained when the child was accompanied by the father and the oral hygiene improved to plaque score of one. On the sixth birthday, the first permanent molars fully erupted, and fissure sealants were put. In the maxillary anterior region, the infected roots of the central incisors were extracted and since the deciduous canines were in position no pontics of deciduous teeth were placed. In African children, the eruption pattern is slightly ahead of the Caucasian and Asiatic populations, and by the sixth birthday, the first permanent lower incisors fully erupted with the maxillary and mandibular incisors [21,22]. A band and loop was placed on the second molars and it rested on the canines in both jaws to minimize the drifting of the erupting first permanent molars and space loss Figure 5-10.

The post-op Diet diary analysis showed that three main meals were consumed in a day with snacking at $10 \mathrm{am}$. The diet was balanced with an increase in the intake of vitamins and proteins. Intake of fermentable carbohydrates (sucrose) was reduced with no intake of doughnuts and cakes as previously reported. The cariogenic foods that persisted included tea/Uji containing sugar and mandazi. The mother reported that the child feeding had improved due to the management of dental pain. The post-treatment nutritional status of the child was assessed, and it was observed that there were slight improvements in the ith the anthropometric parameters. The weight for age had increased by five kilograms, but the child was still below the $3^{\text {rd }}$ percentile, and the WAZ was -2.80 instead of -4.89 SD to the WHO reference standard. The height for age improved by one centimeter the percentile slightly to 0.06 , however, this was still below the $3^{\text {rd }}$ minimum percentile for age and gender. Also, the HAZ score improved slightly to-0.213 which were still below the reference [18]. The Body mass index increase to 13.1 Kilograms per metre square but below the 5 th percentile and the BAZ was improved by half to -2.014 SD of the WHO reference an indication that the child was slowly recovering from the severe malnutrition. It is documented that children who are underweight and they are afflicted with severe-ECC it takes the minimum of 1.38 years to regain the body weight and recover the incremental growth velocity after the oral rehabilitation [24]. The child, in this case, had taken eight months, and there was progress in weight for age, height for age and body mass index for age increase. Similarly the WAz, Haz, BAZ scores improved towards the WHO reference point Table 1 .

Table 1: The anthropogenic measurements for a child with early childhood caries pretreatment and post-treatment.

\begin{tabular}{|c|c|c|c|c|c|c|}
\hline & \multicolumn{3}{|c|}{ Pretreatment } & \multicolumn{3}{|c|}{ Post-treatment } \\
\hline & \multicolumn{3}{|c|}{ Age: 65 months } & \multicolumn{3}{|c|}{ Male Age: 74 months } \\
\hline & Value & percentile & $\begin{array}{c}\mathrm{Z} \\
\text { score }\end{array}$ & Value & percentile & Z score \\
\hline Weight & $14.0 \mathrm{~kg}$ & $\begin{array}{c}0 \% \text { below } \\
3^{\text {rd }} \\
\text { percentile }\end{array}$ & -4.89 & $19.0 \mathrm{~kg}$ & $\begin{array}{c}0.3 \% \\
\text { below } 3^{\text {rd }} \\
\text { percentile }\end{array}$ & $--2.80 \mathrm{SD}$ \\
\hline Height & $118.0 \mathrm{~cm}$ & $\begin{array}{c}1.1 \% \\
\text { below 3rd } \\
\text { percentile }\end{array}$ & -2.3 & $119.0 \mathrm{~cm}$ & $\begin{array}{c}1.7 \% \\
\text { below } 3^{\text {rd }} \\
\text { percentile }\end{array}$ & $-2.13 \mathrm{SD}$ \\
\hline BMI & $\begin{array}{c}10.1 \mathrm{~kg} / \\
\mathrm{m}^{2}\end{array}$ & $\begin{array}{c}0 \% \text { below } \\
5^{\text {th }} \\
\text { percentile }\end{array}$ & -5.68 & $\begin{array}{c}13.4 \mathrm{~kg} / \\
\mathrm{m}^{2}\end{array}$ & $\begin{array}{c}2.1 \% \\
\text { below } 5^{\text {th }} \\
\text { percentile }\end{array}$ & $\begin{array}{c}- \\
2.014 \mathrm{SD}\end{array}$ \\
\hline
\end{tabular}

In this case study, several achievements were made during the treatment where using behaviour management and modification the child showed significant improvement in his behavior from Frankl definitely negative behavior to Positive behavior using nonpharmacological behavior management techniques [19]. The dietary modifications made with the parent resulted in a change in the dietary intake with an improved nutrition status. Currently, the child takes a balanced diet as opposed to a carbohydrate-rich diet, which was previously reported and the cariogenic nutritional intake has also been reduced significantly. The child's intake of meals has also improved due to the elimination of dental pain which was reducing dietary absorption of nutrients. There was improved oral hygiene after the demonstration of tooth brushing techniques as the plaque score has improved from a score of 3 to one [16]. Active carious lesions were controlled and the teeth either restored extracted, and the first permanent molars 36 and which fully erupted had fissure sealants placed [22]. The aesthetics were restored after the unaesthetic carious teeth have been restored using tooth coloured restorations or extracted to give way for the eruption of permanent aesthetic teeth. The child reported he was happy with his new look. Space management was initiated where extraction of grossly carious and infected 64, 74 was done, and band and loops place to maintain space and prevent loss space [21,24]. The challenges with this case were that the child had a severe gagging reflex that made it challenging during impression taking and when taking bilateral bitewings. Behaviour management took time, and the child only felt secure when the father was present hence appointments were made to the father's work schedule of availability this prolonged the treatment period. The parents found the treatment costly although at the dental school the cost is subsidised by the University of Nairobi and they paid only onethird of the cost of treatment for the procedures. The Medical and dental regulatory boy has set necessary charges which are also too 
high for a middle-income Kenya. The child missed school, and the parents were also away from the three station of work which was costly regarding time. Early childhood caries has been reported to interfere with incremental growth velocity of the children afflicted by the condition, due to malnutrition which in the long run compromises the stature of the child in adulthood [25,26,27].

\section{Case Report 2}

\section{Objective}

Treatment of a 4-year-old female patient who presented with Severe Early Childhood Caries. A concise treatment plan including restorative and prosthodontic procedures is presented in this clinical report.

\section{Management}

The patient was given oral hygiene instructions, Motivation and Diet Counseling. The patient underwent complete oral rehabilitation where extractions of $54,52,52,61,62,74$ and 75 were carried out. Composite restorations on $55,53,63,64,65,73,72,82,83$ with 53 and 63 having had indirect pulp cap. The upper and lower partial prosthesis was fabricated as functional spaces. Clinically all sources of potential infections were controlled. The patient had improvement in her ability to feed with regards to chewing. The mother reported that the patient was socializing more and smiled more often. A 4-year-old patient presented accompanied by her mother having been referred from the Minor Oral Surgery clinic for continued management. Their initial presenting complaint was many teeth with decay. The condition had been present for almost two years. The girl was asymptomatic on presentation. However, she was recovering from dental extractions which she had undergone a week earlier on the lower right side. Her past dental history entailed treatment for right submandibular cellulitis secondary to grossly carious 84 and 85 which were treated with antibiotics and drainage by extraction of 84 and 85 . A detailed medical history was taken, but it was noncontributory. The diet history was however significant. There was a definite history of consuming highly cariogenic foods, e.g., cakes, biscuits, soda, artificial fruit juices were consumed on a daily basis. Chocolates and sweets on average were consumed twice a week. There was a history of bottle feeding at three months of age for almost two years. There was a history of sometimes feeding the child at night with the bottle. Lucozade $₫$, Ribena ${ }^{\circledR}, N a n \AA$ formula milk, water with glucose or fresh juice were some of the drinks that she is drunk. The mother reported that she brushed her teeth once in a while or patient brushed herself sometimes without supervision. An extra-oral examination revealed no abnormalities except for palpable bilateral submandibular lymphadenopathy a d her weight was $21.5 \mathrm{kgs}$. An intraoral examination revealed a patient with poor Oral Hygiene with a plaque score of 2.5 (Silness and Loe index [16]). The patient had mild plaque-induced gingivitis with a gingival score of 1.75 [16]. An orthopantomogram revealed a dental age of 4-5 yrs which coincided with her chronological age. Her permanent teeth were present 7's-7 in various stages of tooth development. 7's, 5's, 4's, 3's in crown formation. 6's in root development stage. $52,51,61,62$ beginning root formation. 82,81,71,72 at root formation stage. Physiological root resorption of 52, 51,61,62,71,72,81,82. All deciduous teeth were present except missing 84, 85. There were radiolucencies consistent with dental carious on grossly decayed 540cclusal, 52root, 51root, 61root, 62root, 650, 75 Distal, Occlusal, Mesial grossly decayed with furcation involvement, 74 Distal, Occlusal, Mesial grossly decayed, 73M+D, 72M+D, 81M+D, 82M+D, 83L labial and lingual. Bilateral Bitewings revealed radiolucencies consistent with dental caries on grossly decayed 54 Distal, Occlusal, Mesial with pulpal involvement, 650, grossly decayed with pulpal involvement on 75 Distal, Occlusal, Mesial and 74 Distal, Occlusal, Mesial Missing 84 and 85. An upper standard occlusal radiograph revealed radiolucencies consistent with dental caries with pulpal in involvement for 51,52,61,62. 63 and 73 and the following teeth were in various stages development 16,15,14,12, 11, 21, 22 ,23,24,25,26, in the lower jaw 46,45,44,43,42,41,31,32,33,34,35,36 ,. A diagnosis of a four-year-old African girl in deciduous dentition with severe early childhood caries with a dmft of 20 ; missing 84 and 85 due to caries. There was caries on $55 \mathrm{O}+\mathrm{P}$, grossly carious 54 $\mathrm{D}, \mathrm{O}+\mathrm{M}$. Also, carries on 53L, grossly carious with remaining roots 52, 51, 61, 62, 63Labial, 64Buccal, 650, grossly carious 75 D, 0+ M.. There was grossly carious $74 \mathrm{D}, \mathrm{O}+\mathrm{M}$, carious 73 Distal, Mesial 72 Distal, Mesial, 71M+D, 81M+D,82M+D,83La+ (D=Distal M=Mesial $\mathrm{B}=$ Buccal La=Labial $\mathrm{L}=$ lingual $\mathrm{O}=0$ ccusal $\mathrm{P}=$ Palatal). Tooth 81 and 71 were physiologically mobile with a grade obe mobility the upper second deciduous molar was (55) was supra-erupted.

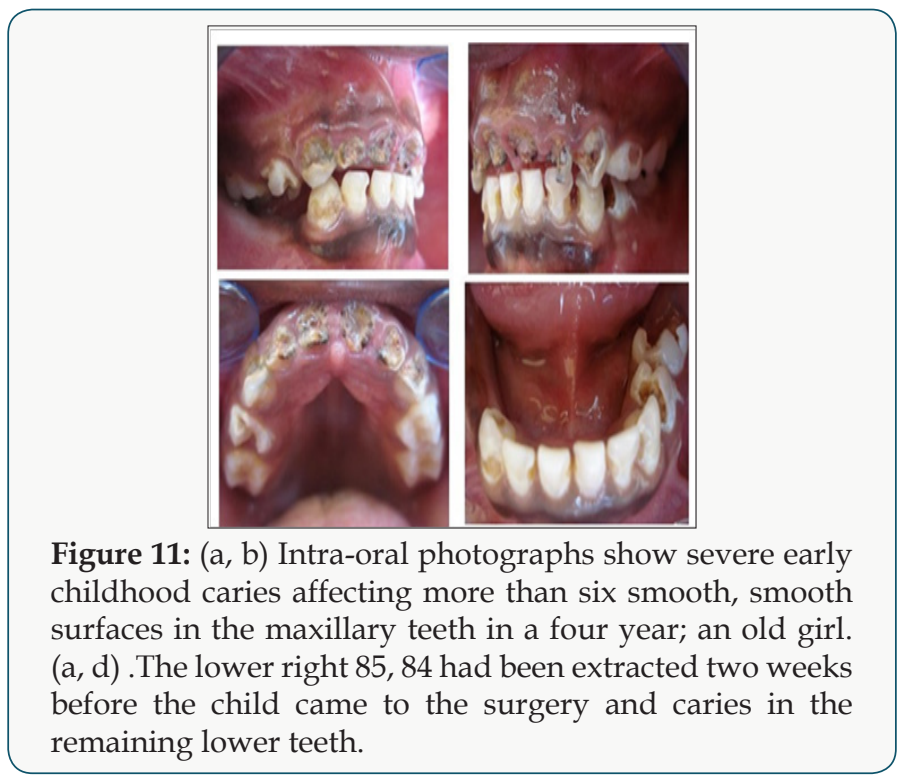

The management of the case involved oral hygiene instructions and diet counseling and Motivation were given to the parent and patient. Oral Prophylaxis was done. There was the extraction of $54,74,75$ and the roots of $52,51,61$, and 62 . The patient was also put on chlorhexidine mouthwash in between dental extractions. Composite restorations on 55 Occlusal, Palatal, 64B, 650, 73 
Distal, Mesial, 72 Distal, Mesial, 82 Distal, Mesial, 83Lingual Labial. Indirect pulp cap with Calcium hydroxide (Dycal®) was done on 53 and 63 and restored with composite restorations. A functional space maintainer in the form of an upper and lower partial denture was fabricated replacing 54, 52, 51, 61, $62+74,75,84,85.71$ and 81 were not restored due to the fact they near exfoliation and the patient was not symptomatic. Despite the current knowledge of dental caries and its etiology, ECC remains a significant health burden; it is a public health challenge with biological, social and behavioural determinants [2]. Given that past caries, the experience is the single most significant predictor of future caries experience; research suggests that interventions need to be aimed at the primary prevention of ECC (Figures 11 \& 12).

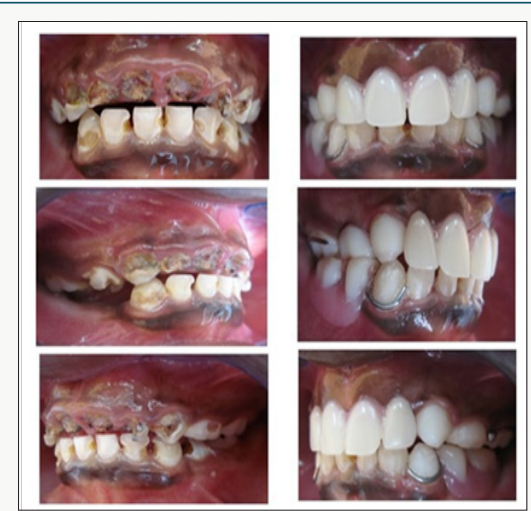

Figure 12: a. Frontal views of photographs showing severe with root remnants of teeth 51,52,61, 62 which were extracted and replaced in the functional space maintainer.

b. Lateral view of the right side of the patient with carious 55,54

c. Tooth 54 was extracted and replaced while 55 had a compomer restoration placed. In the lower jaw missing lower first and second deciduous molars and

d. The left lateral view of the patient showing carious teeth in the upper and lower jaws

e. Tooth $63,64,6575$ and 73 were restored while 74 was extracted and replaced with a tooth pontic. f.

European Association of Pediatric Dentists has clinical recommendations that are based on evidence from the current clinical trials where

i. Oral health assessments with counseling at regularly scheduled visits from the first year of life are an important strategy to prevent ECC.

ii. Children's teeth should be brushed daily with fluoride toothpaste as soon as they erupt.

iii. Professional applications of fluoride varnish twice/year are effective in reducing caries incidence.

iv. Parents of infants and toddlers may be advised and encouraged to reduce behaviors that promote the early transmission of Streptococcus mutans. Chewing xylitol- containing gums during the time of deciduous teeth eruption (6-20 months) may reduce caries in the primary dentition.

v. Frequent intake of sweet drinks the nightly on demand feeding with sweetened baby bottles should be discouraged.

Acs [15]. had shown that before dental rehabilitation, patients with E.C.C had percentile weight categories that were significantly less than that of the comparison group. In the study $13.7 \%$ of the ECC patients weighed less than $80 \%$ of their expected weight for age weight, thereby satisfying one of the criteria for growth stagnation [1]. Impacts include pain, irritability, and disturbed sleeping habits and disturbed sleep may affect neurosteroid production and growth $[25,28]$. Affects general health, it significantly impacts on the quality of life of children and their dietary intake. Children with untreated ECC had the considerably poorer oral health- related quality of life than children without ECC $[25,28]$ The consequences of ECC include a higher risk of hospitalisations and emergency dental visits, increased days with restricted activity and absence from school and a diminished ability to learn [29,30]. Dental pain has an impact not only on the child's educational development but also on the economy due to the time is taken off by parents to take children to the dentist. Dental treatment makes a very significant difference to the psychological and social aspects of the child's life. These improvements include less pain and improved abilities to eat and sleep. The perception of parents to treatment had positive social impacts on their child: more smiling, improved school performance and increased social interaction.

\section{References}

1. (2002) Guideline on Caries-risk Assessment and Management for Infants, Children, and Adolescents. Clinical Practice Guidelines 37(6): 15-16.

2. O'Sullivan DM, Tinanoff $N$ (1993) Social, and biological factors are contributing to caries of the anterior maxillary teeth. Pediatr Dent 15(1):41-44.

3. (2006) J Indian Soc. Pedod Prev Dent. 24(4): 173-176.

4. Mouradian, Wendy E (2001) “The face of a child: children's oral health and dental education. Journal of dental education 65(9): 821-831.

5. Milnes AR (1996) Description and epidemiology of nursing caries. J Public Health Dent 56(1): 38-50.

6. Ngatia (2001) Dietary Patterns and dental caries in nursery school children in Nairobi, Kenya. East Afr Med J 78(12): 673-677.

7. Masiga M (1993) The prevalence of dental caries and gingivitis and their relationship to social class amongst nursery school going children in Nairobi, Kenya. Int J Paed Dent 3(3): 135-140.

8. Çolak H, Dülgergil ÇT, Dalli M, Hamidi MM (2013) Early childhood caries updates: A review of causes, diagnoses, and treatments. J Nat Sc Biol Med $4(1): 29-38$.

9. Kakanur M, Nayak M, Patil SS, Thakur R, Paul ST, Tewathia N (2017) Exploring the multitude of risk factors associated with early childhood caries. Indian J Dent Res 28(1): 27-32.

10. Kanasi E (2010) Clonal Analysis of the Microbiota of Severe Early Childhood Caries. Caries Research 44(5): 485-497. 
11. Tanner (2011) Cultivable Anaerobic Micro-biota of Severe Early Childhood Caries. Journal of Clinical Microbiology 49(4): 1464-1474.

12. Gussy (2006) Early childhood caries: Current evidence for etiology and prevention. Journal of Paediatrics and Child Health 42(1-2): 37-43.

13. Slade GD (1996) Influence of exposure to fluoridated water on socioeconomic inequalities in children's caries experiences Community. Dent Oral Epidemiol 24(2): 89-100.

14. O'Sullivan DM (1996) The association of early childhood caries patterns with caries incidence in preschool children. J Pub Health Dent 56: 81-83.

15. Acs G (1999) The effect of dental rehabilitation on the body weight of children with early childhood caries. Pediatr Dent 21(2): 109-113.

16. Silness J, Loe H (1964) Periodontal disease in pregnancy 2. Correlation between oral hygiene and periodontal condition. Acta Odontol Scand 22 121-135.

17. Loe H, Silness (1963) Periodontal Disease in Pregnancy. Prevalence and Severity. Acta Odontol Scand 21: 533-551.

18. World health organisation (WHO) (1995) Physical status: the use and interpretation of anthropometry. Report of a WHO Expert Committee 854: $1-452$.

19. Frankl SN (1962) Should, the parent, remain with the child in the dental operatory? J Dent Child 29: 150-163.

20. Wright GZ (1975) Non-pharmacological behaviour management: Behaviour management in dentistry for children. WB Saunders Company.

21. Alnahwi HH, Donly KJ, Contreras CI (2015) Space Loss after Premature Loss of Primary Incisor. Gen Dent 63(6): e1-4.
22. Hassanali J, Odhiambo JW (1981) Ages of the eruption of the permanent teeth in Kenyan African and Asian children. Ann Hum Biol 8(5): 425-434.

23. Hassanali J \& Odhiambo JW (1982) Estimation of calendar age from eruption times of permanent teeth in Kenyan Africans and Asians. Annals of Human Biology 9(2):175-177.

24. Gurusamy K, Raju Os, Krishna PT (2011) Oral Rehabilitation of an S-ECC Case with Orthodontic Intervention: 18 Months Follow-up. Int J Clin Pediatr Dent 4(2):153-157.

25. Sheiham A (2006) Dental caries affects body weight, growth, and quality of life in pre- school children. British Dental Journal 201(10): 625-626.

26. Edalat A, Abbaszadeh M, Eesvandi M, Heidari A (2014) The Relationship of Severe Early Childhood Caries and Body Mass Index in a Group of 3- to 6-year-old Children in Shiraz. J Dent (Shiraz) 15(2): 68-73.

27. Sachdev J (2016) Effect of Comprehensive Dental Rehabilitation on Growth Parameters in Pediatric Patients with Severe Early Childhood Caries. Int J Clin Pediatr Dent 9(1): 15-20.

28. Low W, Tan S, Schwartz S (1999) The effect of severe caries on the quality of life in young children. Pediatr Dent 21(6): 325-326.

29. Tennant M, Namjoshi D, Silva D, Codde J (2000) Oral health and hospitalization in Western Australian children. Aust Dent J 45: 204-207.

30. Scorca (2013) An Early childhood caries (ECC) and neglect in child care: Analysis of an Italian sample. La Clinica terapeutica 164(5): e365-e371.
(C) (P) This work is licensed under Creative

To Submit Your Article Click Here: Submit Article

DOI: $10.32474 /$ MADOHC.2018.02.000135

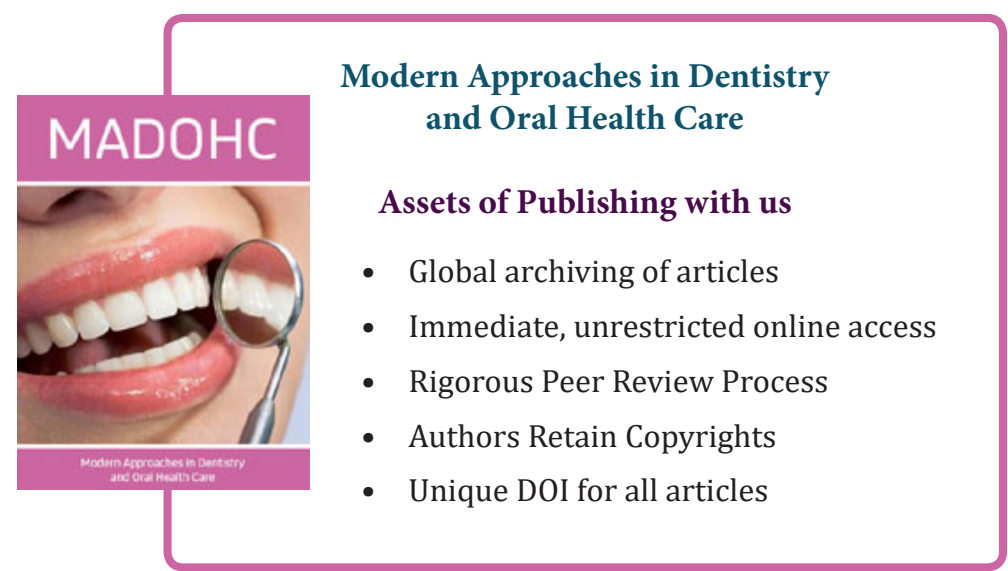

